\title{
PENGELOLAAN OBJEK WISATA PANTAI BUMBANG BERBASIS MASYARAKAT DI DESA MERTAK KECAMATAN PUJUT KABUPATEN LOMBOK TENGAH
}

\author{
Farel Ahadyatulakbar Aditama ${ }^{1}$, Nur Tazkirah², Eni Febriani ${ }^{3}$, Syarif Husni ${ }^{4 \star}$ \\ 1 Fakultas Matematika dan IImu Pengetahuan Alam Universitas Mataram \\ ${ }^{2}$ Fakultas Peternakan Universitas Mataram \\ 3 Fakultas Pertanian Universitas Mataram \\ ${ }^{4}$ Fakultas Pertanian Universitas Mataram \\ ${ }^{*}$ Co-Author : syarifhusni964@gmail.com
}

\begin{abstract}
ABSTRAK. Pariwisata Lombok merupakan sebuah potensi besar yang harus di kelola denga maksimal, akan tetapi dalam pengelolaan sering kali terkendala berbagai hal seperti kurangnya kesadaran masyarakat akan potensi pariwisata yang ada dan keterbatasan pengetahuan dalam hal pengelolaan. Kedua hal ini membuat pariwisata yang ada di Desa Mertak kurang berkembang tidak terkecuali Pantai Bumbang. Tujuan kegiatan pengabdian pada masyarakat adalah melakukan sosialisasi tentang potensi pariwisata desa, pengelolaan wisata, pembuatan awik-awik serta perencanaan pengembangan Kawasan wisata di Desa Mertak. Metode kegiatan pengabdian menggunakan metode sosialisasi, dan metode Focuss Group Discussion (FGD)/Diskusi Kelompok Terarah, yaitu metode dalam pengumpulan data dan informasi mengenai masalah tertentu yang sangat spesifik melalui diskusi kelompok. Hasil dari kegiatan ini adalah meningkatnya pemahaman dan kesadaran masyarakat di Desa Mertak akan pentingnya pengelolaan objek wisata yang mandiri dengan semakin pesatnya perkembangan parawisata yang ada di Lombok, tersusunnya awik-awik untuk pengelolaan objek wisata khususnya Pantai Bumbang dan meningkatnya jumlah fasilitas umum di sekitaran Pantai Bumbang serta terbentuknya perencanaan berupa Grand Design.
\end{abstract}

Kata Kunci: strategi, pengembangan, peraturan, pariwisata

ABSTRACT. Lombok tourism is a great potential that must be managed maximally, but in management it is often constrained by various things such as lack of public awareness of the existing tourism potential and limited knowledge in terms of management. Both of these make tourism in the village of Mertak less developed, including Bumbang Beach. The purpose of community service activities is to socialize the potential of village tourism, tourism management, building awareness and planning the development of tourist areas in Mertak Village. The method of service activities uses socialization methods, and the Focuss Group Discussion (FGD) method, which is a method of collecting data and information on specific issues that are very specific through group discussions. The results of this activity are the increased understanding and awareness of the people in Mertak Village on the importance of managing independent tourism objects with the increasingly rapid development of tourism in Lombok, the lay-up of management of tourism objects, especially Bumbang Beach and the increasing number of public facilities around Bumbang Beach and the formation of planning in the form of Grand Design..

Keyword: strategy, development, regulation, tourism 


\section{PENDAHULUAN}

Pariwisata menjadi salah satu primadona bagi negara-negara dalam meningkatkan sumber pendapatannya diluar dari migas dan pajak. Saat ini Indonesia sebagai salah satu negara berkembang mulai mempromosikan negaranya guna menarik pandangan mata dunia lain, hal ini dimaksudkan agar Indonesia semakin terkenal bagi warga/penduduk negara lain untuk berkunjung ke Indonesia (Suwantoro, 1997). Promosi-promosi yang dilakukan adalah menjual keragaman wisata dan budaya Indonesia, hal inilah ditanggapi positif dengan banyaknya wisatawan dari mancanegara yang berkunjung ke Indonesia (Pendit, 1999).

Indonesia yang memiliki keragaman budaya dan wisata melimpah itu mampu mengatasi masalah-masalah mendasar dengan penguatan ekonomi dari penerimaan devisa/pendapatan daerahnya dengan itulah sebagai negara yang memiliki keragaman melimpah Indonesia dapat mengembangkan potensinya, misalnya dari segi pariwisata sebab wisatawan yang berkunjung ke Indonesia mencari atau menikmati keindahan pariwisata Indonesia sehingga memberikan efek domino bagi dalam maupun luar negeri, bila dari luar negeri negara kita semakin terkenal maka bagi dalam negeri negara kita dapat menambah devisa guna mengangkat kesejahteraan masyarakat yang ada saat ini.

Pariwisata memiliki peran yang besar dalam pembangunan nasional. Karena selain menghasilkan pendapatan dan sekaligus sebagai penghasil devisa, sektor pariwisata berkaitan erat dengan penanaman modal asing. Turis-turis yang datang ke Indonesia adalah termasuk mereka yang berhubungan bisnis dengan Indonesia.

Usaha pariwisata adalah kegiatan yang bertujuan menyelenggarakan jasa pariwisata atau menyediakan atau mengusahakan objek dan daya tarik wisata, usaha barang pariwisata dan usaha lain yang terkait dengan bidang tersebut. Industri pariwisata adalah suatu susunan organisasi, baik pemerintah maupun swasta, yang terkait dalam pengembangan, produksi dan pemasaran produk suatu layanan untuk memenuhi kebutuhan dari orang yang sedang berpergian (Wahab, 1997).

Pariwisata di daerah-daerah sangatlah banyak bila mampu memanfaatkan potensi-potensi yang ada, pemerintah dan masyarakat daerah saling membantu dalam pengembangannya tersebut sehingga akan mengangkat segi ekonomi, budaya dan pendidikan daerah itu. Pariwisata sangatlah mampu dalam mengatasi masalah kesejahteraan bila dikembangkan secara propesional (Situmorang, 2001).

Dalam pengembangan pariwisata tidak hanya pemerintah yang melakukan sendiri tetapi pihak-pihak lain juga ikut andil dalam pembangunan infrastruktur pendamping, ini guna meningkatkan pendapatan dari sektor ekonominya. Menurut Charles Kaiser Jr. Dan larry E. Helber dalam bukunya menjelaskan tingkat-tingkat perencanaan pariwisata itu dimulai dari pengembangan pariwisata daerah yang mencakup pembangunan fisik objek dan atraksi wisata. Setelah itulah dilakukan, kita akan dapat melihat bagaimana perkembangan dari jumlah berkunjung wisatawan apabila ternyata mencapai target yang telah ditetapkan selanjutnya akan memikirkan sistem prioritas. Untuk pengembangan ini perlu dilakukan pendekatan-pendekatan dengan organisasi pariwisata yang ada (pemerintah dan swasta) dan pihak-pihak terkait yang diharapkan dapat mendukung kelanjutan pembangunan pariwisata daerah tersebut (Yoeti, 1997).

Pengembangan suatu daerah dapat disesuaikan oleh pemerintah daerah dengan potensi dan kekhasan daerah masing-masing. Ini merupakan kesempatan yang sangat baik bagi pemerintah 
daerah untuk membuktikan kemampuannya dalam melaksanakan kewenangan yang menjadi hak daerah. Maju atau tidaknya suatu daerah sangat ditentukan oleh kemampuan dan kemauan untuk melaksanakan yaitu pemerintah daerah. Pemerintah daerah bebas berkreasi dan berekspresi dalam rangka membangun daerahnya, tentu saja dengan tidak melanggar ketentuan hukum yaitu perundang-undangan (Suwena, 2010).

\section{METODE PELAKSANAAN}

\section{Waktu dan Tempat}

Kegiatan dilakukan selama 45 hari di mulai sejak tanggal 29 Januari 2019 sampai dengan 16 Maret 2019 di Desa Mertak, Kecamatan Pujut, Kabupaten Lombok Tengah.

\section{Metode Kegiatan Pengabdian}

Metode kegiatan yang digunakan dalam pengabdian pada masyarakat adalah melalui Metode Sosialisasi, yaitu metode melalui proses sosial yang terjadi pada seseorang untuk mempelajari dan menyesuaikan diri terhadap norma, nilai, perilaku, adat istiadat, dan semua persyaratan lainnya yang diperlukan agar dapat berperan dan berfungsi dalam kelompoknya. Sosialisasi juga dilakukan dengan memberikan pemahaman dan wawasan masyarakat melalui media gambar dan lefleat dan spanduk.

Selain itu metode yang digunakan juga Metode Focuss Group Discussion (FGD)/Diskusi Kelompok Terarah, yaitu metode dalam pengumpulan data dan informasi mengenai masalah tertentu yang sangat spesifik melalui diskusi kelompok.

Selain sosialisasi dalam kegiatan pengabdian dilakukan beberapa kegiatan penunjang sebagai bentuk peningkatan kesadaran masyarakat seperti pengelolaan objek wisata pantai bumbang serta pembuatan awik-awik pengelolaan pantai.).

\section{HASIL DAN PEMBAHASAN}

\section{Sosialisasi Kegiatan}

Kegiatan sosialisasi ini dilaksanakan pada hari Rabu, 06 Februari 2019 di Aula Kantor Desa Mertak. Sasaran dari kegiatan ini adalah para pemegang kebijakan (stakeholders) dan para tokoh di desa Mertak, seperti Kepala Desa, seluruh kepala Dusun, BPD, POKDARWIS, BUMDES, dan Karang Taruna.

Sosialisasi Strategi Pengembangan Pariwisata Desa Mertak membahas beberapa hal meliputi program kerja usulan tim KKN Tematik di desa Mertak yakni:

\section{Potensi Desa Mertak di Sektor Pariwisata}

Dalam kegiatan sosialisasi ini, masyarakat diberi pengetahuan dan pemahaman mengenai prospek perkembangan pariwisata yang ada di desa Mertak. Kecamatan Pujut terkenal akan nilai budaya yang sangat kental akan adat dan tradisinya. Hal itu ditambah lagi dengan pesona dan keindahan lautan yang membentang luas. Desa Mertak merupakan bagian dari Kawasan Ekonomi (KEK) Mandalika, maka sudah sepatutnya masyarakat desa Mertak mengembangkan Desa melalui potensi-potensi yang terdapat di Desa Mertak. Melalui pemahaman akan prospek perkembangan 
potensi Desa, masyarakat Desa Mertak sadar dan mampu mengembangkan Desa Mertak di bidang Pariwisata.

\section{Grand Design Pengembangan Pariwisata Desa Mertak}

Melihat Desa Mertak kedepannya berpotensi menjadi desa Pariwisata yang akan berkembang pesat, maka sudah seharusnya masyarakat memiliki gambaran mengenai pembangunan desa wisata. Hal tersebut mendorong Tim KKN Tematik membuat sebuah Grand Design Desa Wisata yang pada kesempatan ini Tim KKN memfokuskan dan menjadikan Kawasan Pantai Bumbang sebagai Kawasan percontohan.

Masyarakat diberi gambaran mengenai pembangunan Pantai Bumbang untuk 5 tahun ke depan yang menunjukkan kemajuan pada pembangunan pariwisata yang di lengkapi dengan bangunan dan fasilitas yang memanjakan para pengunjung tanpa meninggalkan nilai budaya sasak Lombok Tengah.

\section{Strategi Promosi, Pemasaran, dan Peraturan Pariwisata Desa}

Kemajuan desa pariwisata tidak luput dari adanya promosi, pemasaran, dan regulasi yang mengaturnya. Di zaman modernisasi saat ini, keberadaan smartphone sangat menguntungkan untuk kegiatan promosi dan pemasaran. Hal tersebut mendorong Tim KKN Tematik menawarkan strategi promosi dan pemasaran desa wisata melalui media sosial dan internet. Seperti pembuatan Website, Instagram, E-Mail dan Youtube.

\section{Pengelolaan Objek Wisata Pantai Bumbang}

Desa Mertak sendiri masih terdapat beberapa objek wisata yang belum dikelola oleh masyarakat maupun desa dengan maksimal, salah satunya adalah pantai Bumbang. Pantai Bumbang terletak di Dusun Bumbang dan Dusun Takar-akar dan juga berada tepat sebelum Kawasan Taman Wisata Alam (TWA) Gunung Tunak. Dengan kondisi Pantai Bumbang yang tidak terlalu terawat membuat Pantai Bumbang jarang dijadikan sebagai tujuan utama wisata. Sehingga, agar Pantai Bumbang dapat memberikan manfaat lebih, kami mengkonsep dan mencoba sistem untuk mengelola Pantai Bumbang. Sistem pengelolaan ini merupakan sistem tahap yang kedepannya masyarakat dapat melanjutkan. Dalam pengelolaan pantai Bumbang terdapat beberapa kegiatan antara lain pembersihan pantai, pembuatan spot foto, promosi dan pemasaran pantai, pembuatan Grand Design, dan pembuatan peraturan Desa Wista berupa Awik-awik khusus Pantai Bumbang.

\section{Penyusunan Awik-awik Pengelolaan Objek Wisata Pantai Bumbang}

Pengelolaan pantai Bumbang memerlukan regulasi yang mengaturnya. Regulasi tersebut berupa Awik-awik pantai juga dibutuhkan dalam pengelolaan pantai Bumbang. Pembuatan awikawik dibuat khusus oleh anggota KKN Tematik UNRAM dari Fakultas Hukum. Dalam pelaksanaanya tim KKN selalu berkonsultasi dengan BKD dan Kepala Desa, serta melakukan diskusi dengan para lembaga mitra dan masyrakat. Awik-awik dibentuk sebagai aturan yang harus dipatuhi dan ditaati oleh setiap orang yang berkunjung maupun pengelola serta masyarakat yang ada disekitar pantai Bumbang. Awik-awik yang dibuat berdasarkan aturan Undang-undang yang berlaku dalam bidang pariwisata sehingga siapapun yang melanggar aturan akan diberikan sanksi sesuai dengan jenis pelanggaran yang dilakukan. Awik-awik dibuat dalam bentuk draft (terlampir) dan diserahkan kepada kepala desa untuk dapat disahkan dan diterapkan. Pembuatan awik-awik pantai Bumbang 
diharapkan dapat menjadi percontohan untuk dapat diterapkan di pantai-pantai lainnya di desa Mertak.

\section{Perencanaan Grand Design Pantai Bumbang}

Melihat desa Mertak merupakan desa KEK Mandalika, maka desa Mertak memiliki peluang dan potensi besar terhadap perkembangan pembangunan kedepannya. Oleh karena itu, tim KKN Tematik membuat dan juga merencakan sebuah konsep Grand Design mengenai pengembangan pariwisata di kawasan pantai Bumbang yang dibuat khusus oleh anggota KKN Tematik UNRAM dari Fakultas Teknik dan serta diskusi oleh tim KKN Tematik sebagai gambaran untuk pembangunan 5 tahun kedepan di Pantai Bumbang. Pengkonsepan dan perancangan Grand Design Pantai Bumbang menggunakan aplikasi Autocad sehingga tata letak untuk masing-masing bangunan telah ditentukan dengan berbagai perhitungan dan pertimbangan. Adapun Grand Design dapat dilihat pada gambar 5.4 di bawah ini.

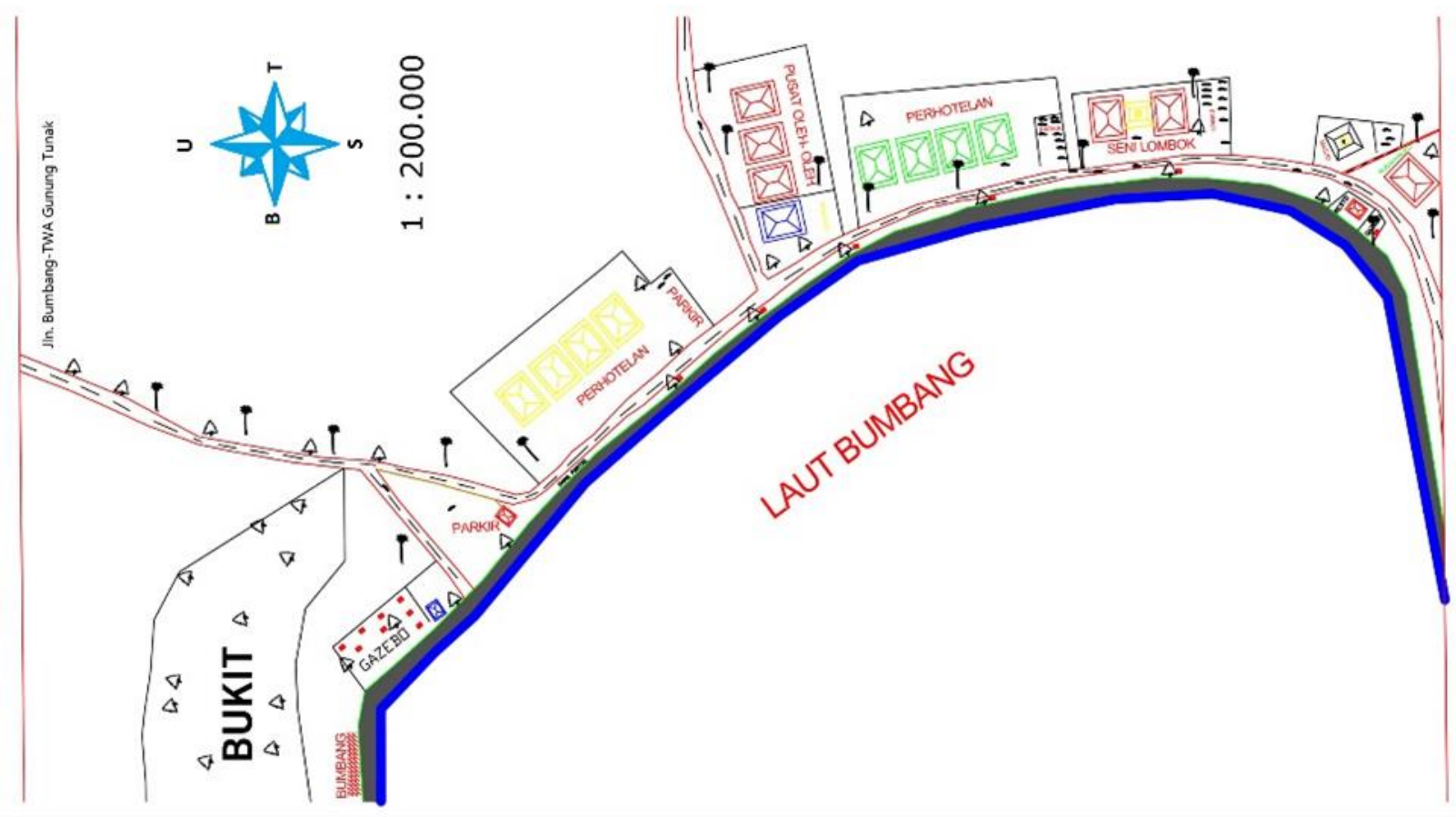

Gambar 1. Grand Design Pengembangan Pantai Bumbang

\section{KESIMPULAN}

Kesimpulan dari kegiatan ini adalah meningkatnya pemahaman dan kesadaran masyarakat di Desa Mertak akan pentingnya pengelolaan objek wisata yang mandiri dengan semakin pesatnya perkembangan parawisata yang ada di Lombok, tersusunnya awik-awik untuk pengelolaan objek wisata khususnya Pantai Bumbang dan meningkatnya jumlah fasilitas umum di sekitaran Pantai Bumbang serta terbentuknya perencanaan berupa Grand Design.

\section{REFERENSI}

Hadinoto, Kusudianto. 1996. Perencanaan Pengembangan Destinasi Pariwisata. Jakarta: UI-Press.

Horrison, Lisa. 2007. Metodelogi Penelitian Politik. Jakarta : Kencana Pernada Group.

Pendit, N S. 1999. IImu Pariwisata: Sebuah Pengantar Perdana. Jakarta: Pradnya Paramita

Pitana, I Gde., and I Ketut Surya Diarta. 2009. Pengantar Ilmu Pariwisata. Yogyakarta: Andi. 
Situmorang, Rahel. 2001. Perencanaan dan Pengembangan Wisata Pantai Berwawasan Lingkungan, Bina Wisata Nusantara, 6(1) $77-84$.

Spillane, James J. 1994. Pariwisata Indonesia: Siasat Ekonomi dan Rekayasa Kebudayaan. Yogyakarta: Kanisius.

Suwantoro, Gamal. 1997. Dasar-Dasar Pariwisata. Yogyakarta: Andi.

Suwena, I ketut., and I Gst Ngr Widyatmaja. 2010. Pengetahuan Dasar Ilmu Pariwisata. Denpasar: Udayana University Press.

Yoeti, Oka A. 1997. Perencanaan dan Pengembangan Pariwisata. Jakarta: Pradnya Paramita,.

Wahab, Salah. 1997. Pemasaran Pariwisata. Jakarta: Pradnya Paramita. 